\title{
ANTECIPAÇÃO DE TUTELA E SUAS MUDANÇAS DO ATUAL AO NOVO CÓDIGO DE PROCESSO CIVIL LEI
} $13.105 / 2015$

ANTICIPATION DE GUARANTEE AND ITS CHANGES FROM THE CURRENT TO THE NEW CIVIL PROCESS CODE LAW 13.105 / 2015

\section{Erisson Ronaldo Tonial ${ }^{1}$}

ISSUE DOI: $10.21207 / 1983.4225 .436$

\section{RESUMO}

O presente trabalho tem por objetivo fazer uma análise minuciosa e comparativa da tutela antecipada, descrevendo o que mudou do antigo código de processo civil, para o novo código de processo civil, suas melhorias, benefícios, será estudado a tutela antecipada, análise do antigo e novo código de processo civil, apontando as mudanças que ocorreram diante da Lei 13.105/2015.

Palavras-chave: Tutela Antecipada. Estudo. Análise. Novo CPC. Velho CPC. Comparativo. 


\section{ABSTRACT}

O presente trabalho tem por objetivo fazer uma análise minuciosa e comparativa da tutela antecipada, descrevendo o que mudou do antigo código de processo civil, para o novo código de processo civil, suas melhorias, benefícios, será estudado a tutela antecipada, análise do antigo e novo código de processo civil, apontando as mudanças que ocorreram diante da Lei 13.105/2015.

Keywords: Injunctive Relief. Study. Analysis. New CPC. CPC Old. Comparative.

\section{INTRODUÇÃO}

Presente trabalho a ser elaborado, reflete o estudo, análise, da antecipação da tutela ou tutela antecipada. Vamos verificar o que mudou, o que se conserva no presente recurso que tanto é pleiteado em nossas comarcas e tribunais. E ainda a comparação com o antigo código e novo código de processo civil lei ${ }^{\circ} 13.105 / 2015$.

\section{DA TUTELA E SUA EVOLUÇÃO NO CPC/1973}

O conceito que sabemos sobre tutela se dirige quando o Juiz, por meio de uma decisão interlocutória, que adianta ao postulante, total ou parcialmente, os efeitos do julgamento de mérito, quer em primeira instância quer em sede de recurso. Esclarece tal ordenamento jurídico, que primeiramente serve para acelerar e ao mesmo tempo proporciona uma maior efetividade à prestação jurisdicional, diante da vagarosidade que transcorre o processo em sua normalidade. Devemos deixar claro que não podemos confundir com a medida cautelar, que no caso, busca resguardar algo no decorrer do processo, enquanto a tutela tenta antecipar, adiantar um direito que é almejável.

\subsection{EVOLUÇÃO DA TUTELA DENTRO DO CPC/1973}


A parte da tutela cautelar que resguardava o CPC/1973, era destinado a três tipos de processo, tal divisão era elaborada da seguinte forma, se não vejamos: a primeira chamada de (conhecimento), direcionado a dar ao nobre julgador os subterfúgios a altura de sua necessidade para que elaborasse um julgamento, que ficasse claro em seu parecer a lei do caso concreto. $\mathrm{O}$ segundo chamado de (execução), determinado diretamente a satisfação do direito do credor em cima do devedor, quando o mesmo não cumpria com o seu dever voluntariamente na apreciação dos títulos executivos; e por último o (cautelar), designado como acessório, sua função principal era de proteger os dois institutos que eram ameaçados pela demora do trâmite processual.

A cada um deles era lhe descrito um tipo de processo, mas o processo cautelar coube lhe apreciar um livro inteiro do antigo código de processo civil o LIVRO III do CPC/1973. A cada tipo de tutela como já referido, era determinado um tipo de processo para a mesma, diante disso se um indivíduo na relação processual necessita-se de uma medida de tutela de cunho cautelar não poderia pleiteá lá, no atual sistema original do CPC/1973, dentro do processo de conhecimento, todavia deveria insurgir no processo cautelar de características incidentais e de preparação, sendo essa parte de forma autônoma em relação ao processo principal, de conhecimento ou de execução. No momento da reformulação do CPC/1973, não surgia possibilidades ao deferir tutelas provisórias genéricas de caráter satisfativo, existia, sim, alguns procedimentos especiais que antecipavam concessões de medidas satisfativas em caráter liminar, como as ações possessórias, nunciação a obra, embargos de terceiro, etc. Subtraindo essas ações como foi exemplificado não havia o deferimento das tutelas provisórias em caráter satisfativo.

A grande mudança trazida pela Lei 8.952/94, onde deu nova inspiração a redação do art. $273 \mathrm{CPC} / 1973$, dentre as inúmeras reformas pelas quais o mesmo dispositivo passou, durante seu trâmite de vigência, pois diante desta mudança passou a admitir o deferimento das tutelas genéricas satisfativas em praticamente todos os tipos de processo e também, todos os tipos de procedimento, contudo deveria ser preenchidos todos os pré-requisitos estabelecidos por determinado dispositivo.

Perante tal mudança passou-se a existir no ordenamento jurídico dois tipos de tutela a antecipada (satisfativa) e a cautelar. Para tal feito, a distinção só foi efetuada, por causa do provimento de medidas cautelares onde se pedia um procedimento autônomo para o ajuizamento do processo cautelar, já que se exigia um habitat para as solicitações das providências 
acautelatórias. Caminhando no mesmo segmento ocorria a postulação das tutelas satisfativas já no processo principal, acabando assim com o processo autônomo.

Ocorreria uma nova mudança rapidamente estampada pela Lei n. 10.444/2002, onde deu nova descrição ao $\S 7^{\circ}$ do seu respectivo art. 273 , tal mudança foi muito importante, pois possibilitou ao magistrado, ainda que fosse deferida a tutela antecipada, conceder se entendesse em seu juízo apropriado, uma cautelar junto ao processo principal. Deste modo podemos caraterizar um modelo fungível entre os dois tipos de tutela, sendo a mesma diferenciada dando ao magistrado inúmeras e maiores condições de proferir a medida mais adequada para distanciar uma situação de perigo no caso concreto em que foi submetido.

A fungibilidade das tutelas entre si, autorizava o magistrado a deferir as medidas cautelares dentro do trâmite processual principal, sem a necessidade de um segundo processo, determinado autônomo, concluindo o ajuizamento do processo cautelar era devido a não permissão de seu julgamento pelo magistrado no processo principal, sendo que dentro da inovação legislativa na época o processo cautelar não tinha mais sustentação. Contudo mesmo ainda dentro da sua vigência, o CPC/1973, admitia aos magistrados o ajuizamento de processos cautelares autônomos, em destaque de caráter preparatório, quando o processo principal não se encontrava dentro do conhecimento do magistrado. Pela sensibilidade do legislador, ocorreu que pelas mudanças designadas não haveria justificativa para a insistência do processo cautelar em caráter autônomo, mas a designação do que antecede o processo principal.

Concluindo o breve esboço, embora o CPC de 1973, mantinha a distância entre a tutela de procedimento cautelar e a tutela de procedimento antecipado passou a avaliá-las e a caracterizá-las em mesmo gênero e espécie. No sistema antigo processual de 1973, não havia necessidade de consideração da fungibilidade das medidas tutelares processuais, sendo que as mesmas se unem em gênero e espécie das tutelas provisórias, ficando assim o magistrado a deferir a medida mais adequada no caso concreto que lhe padecer. CPC(ART. 297/1973). Diante da efetivação da Lei 13.105/2015 a tutela provisória está descrita em seus art. 294 à 311 do novo código de processo civil.

\section{TUTELA PROVISÓRIA}


Descrita em seu art. 294 CPC/2015, em seu parágrafo único, onde estabelece claramente suas diferenças. Como tutela provisória descreve um dos membros da comissão dos juristas do senado o grandioso Elpídio Dourizette estabelece assim sua divisão:

Tutela Provisória é gênero, que contempla duas espécies: tutela satisfativa (denominada antecipada) e cautelar. O CPC de 2015 eliminou o processo cautelar autônomo, incluindo o rol das cautelares típicas. Contudo a tutela cautelar continua firme e forte. ${ }^{2}$

Referente jurista aborda basicamente a divisão da tutela provisória com sua divisão elencada na explicação, ainda ressalta a exclusão do processo autônomo, onde foi de suma importância tal mudança, pois no atual código de processo civil, o extinto processo autônomo corre com a lide principal, facilitando assim para o magistrado a conclusão do direito a ser pleiteado, e ainda respeita assim, o tempo de processo a ser cumprido, onde do modo antigo pelo sistema de 1973 era longo, e pelo atual código de 2015 deverá subtrair tempo para a maior celeridade, e economia processual. Ainda no mesmo raciocínio Freddie Diddier Jr. ressalta:

A tutela jurisdicional oferecida pelo Estado-juiz pode ser definitiva ou provisória. Este capítulo é dedicado à tutela provisória; para entendê-la, é preciso compreender a tutela definitiva. Isso porque a tutela provisória é a tutela que se pretende definitiva concedida após cognição sumária. ${ }^{3}$

No mesmo raciocínio Dr. Freddie, faz uma ligação entre a tutela jurisdicional, onde para entender a provisória devemos entender a definitiva por causa da cognição sumária, onde veremos no transcrever do presente tópico.

${ }^{2}$ DONIZETTI. Elpídio. Curso Didático de Direito Processual Civil. $19^{\circ}$ E. São Paulo: Atlas, 2016. p. 456.

${ }^{3}$ DIDDIER JR. Freddie. Curso de Direito Processual Civil. Teoria da Prova, Direito Probatório, Decisão, Precedente, Coisa Julgada e Tutela Provisória $10^{\circ} \mathrm{Ed}$. 2015. Jus provim. Salvador. p. 561. 
A tutela definitiva é adquirida pela cognição exauriente, onde ela se destaca pelo profundo debate da questão, acerca do objeto da decisão, deste modo garante o devido processo legal, o contraditório e a ampla defesa. Sendo assim de forma ambiciosa a busca da garantia de resultados definitivos, concretizados pela decisão de mérito. De mesmo modo a tutela definitiva se subdivide-se em:

- Tutela Definitiva Satisfativa - Caracteriza-se na efetivação do direito material com a entrega do bem da vida que o almeja, conhecida como tutela padrão.

- A mesma ramifica-se em uma tutela de certificação de direitos, que pode ser (declaratória, constitutiva e condenatória), e também pela sua efetividade de seus direitos (tutela executiva) em seu sentido amplo. Para confirmação da explanação Freddie Diddier destaca:

A tutela definitiva pode ser satisfativa ou cautelar. A tutela definitiva satisfativa é aquela que visa certificar e/ou efetivar o direito material. Predispõe-se à satisfação de um direito material com a entrega do bem da vida almejado. É a chamada tutela-padrão Há dois diferentes tipos de tutela definitiva satisfativa: a tutela de certificação de direitos (declaratória, constitutiva e condenatória) e a tutela de efetivação dos direitos (tutela executiva, em sentido amplo). ${ }^{4}$

Perante a ambição de adquirir as atividades processuais da tutela padrão (tutela satisfativa), poderão ser vagarosas em seu objetivo de alcançar, o direito almejado o que de uma certa forma poderá frustrar a realização dele ser adquirido, surgindo assim o periculum in mora, ou mais conhecido como o perigo da demora, referente a prestação jurisdicional.

Contudo devido a essa demora, e consequentemente a frustração da conquista do direito afirmado forma-se a tutela não satisfativa, onde o mesmo não satisfaz por completo a parte que almeja o bem em debate processual a ser alcançado, cujo o cunho é de característica assecuratória, que

${ }^{4}$ DIDDIER JR. Freddie. Curso de Direito Processual Civil. Teoria da Prova, Direito Probatório, Decisão, Precedente, Coisa Julgada e Tutela Provisória. $10^{\circ}$ Ed. 2015. Jus provim. Salvador. p. 562. 
serve para resguardar o direito afirmado e com isso, paralisar os efeitos prejudiciais do tempo (a tutela cautelar). Diante do exposto Marcus Vinícius Rios Gonçalves, reafirma a consistência da tutela satisfativa mesmo em caráter provisório, afirmando que a mesma não satisfaz totalmente o autor nem um todo ou em parte diante da sua pretensão se não vejamos o que o nobre autor fala:

A tutela provisória cautelar não satisfaz, no todo ou em parte, a pretensão do autor. O juiz não concede, já, o que só seria deferido ao final, mas determina providências de resguardo, proteção e preservação dos direitos em litígio. Imagine-se que o autor proponha em face do réu uma ação de reintegração de posse. Se o juiz concedê-la liminarmente, a medida será de antecipação satisfativa, já que o autor obterá aquilo que constitui a sua pretensão. Há coincidência entre o que foi pedido e o que foi deferido de imediato. ${ }^{5}$

\subsection{CARACTERÍSTICAS DA TUTELA PROVISÓRIA CAUTELAR.}

As características da tutela provisória em especial a cautelar, refere-se não só pela diferença da satisfativa (que veremos no próximo tópico), mas pela referência e o tempo ao qual denota-se em dois princípios. O Princípio da Referibilidade da tutela provisória cautelar destaca-se pela preservação de outro direito, onde o mesmo é diferente do principal almejado dentro da cautela, ou seja, dentro do processo cautelar, como já vimos no descrever deste trabalho, em seu conceito puro a antecipação de tutela no que diz respeito à tutela provisória, é a antecipação de um direito pleiteado, diferente do principal, onde ocorre dentro do processo. Dentro disso há vários direitos cautelares que o indivíduo requer em hipótese de pleno direito, que será avaliado pelo magistrado. A referibilidade aqui é que o direito à cautela é o direito à tutela cautelar; o direito a que se cautela, ou

\footnotetext{
${ }^{5}$ RIOS, Marcus Vinícius Gonçalves; Direito Processual Civil Brasileiro. Ed. Saraiva. São Paulo. $6^{\circ}$ Edição, 2016. p. 350.
} 
direito acautelado, é o direito que recai a tutela cautelar, daí se dá a referibilidade. Mas o Ilustríssimo autor, Advogado, Professor Freddie Diddie explicará melhor:

A tutela cautelar é meio de preservação de outro direito, o direito acautelado, objeto da tutela satisfativa. A tutela cautelar é, necessariamente, uma tutela que se refere a outro direito, distinto do direito à própria cautela. Há o direito à cautela e o direito que se acautela. $\mathrm{O}$ direito à cautela é o direito à tutela cautelar; o direito que se acautela, ou direito acautelado, é o direito sobre que recai a tutela cautelar. Essa referibilidade é essencial. Um exemplo: o arresto de dinheiro do devedor inadimplente é instrumento assecuratório do direito de crédito do credor. O direito de crédito é o direito acautelado; o direito à cautela é o direito à utilização de um instrumento processual que assegure o direito de crédito. ${ }^{6}$

Diante disso acaba-se presumindo-se a sua definição, durando o tempo necessário até a sua objetividade, o alcance da tutela satisfativa. Sendo assim como vimos a tutela cautelar decorre de definição (temporário), não sendo provisório, pois nada virá ao seu lugar em proporção de mesma natureza, tornando-se assim uma tutela assecuratória definitiva, inalterando o bem da vida. Tendo como efeitos são por características limitados, onde cedo ou tarde cessarão. Do que diz respeito a coisa julgada dentro da antecipação de tutela, podemos destacar que o tempo (temporalidade) como vimos acima, não toma o lugar de sua definitividade. Em sua demanda na ação cautelar de antecipação de tutela composto por 3 requisitos de praxe dentro do trâmite processual: pedido, causa de pedir e objeto.

Do pedido refere-se a segurança, da causa de pedir destaca-se o almejo do direito a ser acautelado e o perigo da demora do trâmite processual no que se refere ao direito à cautela. Em suma a questão da definição

${ }^{6}$ DIDDIER JR. Freddie. Curso De Direito Processual Civil. Teoria da Prova, Direito Probatório, Decisão, Precedente, Coisa Julgada e Tutela Provisória. $10^{\circ}$ Ed. 2015. Jusprovim. Salvador. pp. 562-563. 
ou dar o nome da TUTELA PROVISÓRIA, dentro do dinamismo do segmento da CAUTELAR ou da ANTECIPADA, sistematiza ao provimento jurisdicional que visa adiantar os efeitos da decisão final no processo ou assegurar o seu resultado prático.

Ainda nisso à exigência de dois requisitos, a probabilidade do direito substancial (chamado fumus boni iuris), e o perigo de dano ou o risco do resultado útil do processo (periculum in mora), soma desses quesitos, transforma-se em uma fórmula onde a igualdade deve-se equivaler-se em $100 \%$, onde há uma compensação mútua entre si. Se a ação de antecipação de tutela tiver caráter de extrema urgência que afete ou cause algum dano ao direito substancial ou provoque algum risco no resultado final do processo. Em relação a sua probabilidade diminui o nível de exigência. Contudo aumentam as chances do direito substancial diminuindo assim seu grau de exigência. Explica Melhor um dos Membros da Comissão dos Juristas do Senado Federal o Elpídio Donizetti:

Dá-se o nome de Tutela Provisória ao provimento jurisdicional que visa adiantar os efeitos da decisão final no processo ou assegurar o seu resultado prático. A tutela provisória (cautelar ou antecipada) exige dois requisitos: a probabilidade do direito substancial (o chamado fumus boni iuris) e o perigo de dano ou o risco do resultado útil do processo (periculum in mora). A soma desses dois requisitos deve ser igual a $100 \%$, de forma que um compensa o outro. Se a urgência é muito acentuada (perigo de dano ao direito substancial ao risco de resultado útil do processo), a exigência quanto à probabilidade diminui. Ao revés, se a probabilidade do direito substancial é proeminente, diminui-se o grau da exigência. ${ }^{7}$

\subsection{CARACTERÍSTICAS DA TUTELA PROVISÓRIA.}

${ }^{7}$ DONIZETTI. Elpídio. Curso Didático de Direito Processual Civil. $19^{\circ}$ Ed. Atlas. SP. 2016, p. 456. 
Caracterizando a TUTELA PROVISÓRIA podemos destacar em primeiro lugar sua sumariedade da cognição, visto que pelo intuito cognitivo, a análise do processo no que se refere ao seu objeto, da poderes ao juiz que julgue a partir do juízo de probabilidade. $\mathrm{O}$ em segundo lugar pela sua precariedade onde se baseia pelo princípio da tutela provisória, na função de preservar a sua eficácia no decorrer do processo, ainda ressalva a hipótese de decisão judicial em sentido contrário, redigido pelo § único do art. 296, caput, CPC/2015. Quanto a sua modificação ou revogação só poderá ocorrer, quando sofrer uma alteração em seu estado de fato de direito ou em seu estado de prova, onde na instrução por exemplo, ficarem evidenciados fatos que não correspondam ao daqueles que confirmam a autorização da tutela. Assim explica Professor e Adv. Freddie Diddier Jr:

A revogação ou modificação de uma tutela provisória só pode dar-se, porém, em razão de uma alteração do estado de fato ou de direito ou do estado de prova quando, por exemplo, na fase de instrução, restarem evidenciados fatos que não correspondam àqueles que autorizaram a concessão da tutela. ${ }^{8}$

E por fim a última característica, quando nasce a cognição sumária e precária que nada mais é segundo Kazuo Watanabe citado pelo professor Freddier Diddier Jr.:

provalentemente um ato de inteligência, consistente em considerar, analisar e valorar as alegações e as provas produzidas pelas partes, vale dizer, as questões de fato e as de direito que são deduzidas no processo e cujo resultado é o alicerce, o fundamento do utdicium, do julgamento do objeto litigioso do processo. ${ }^{9}$

\footnotetext{
${ }^{8}$ DIDDIER JR. Freddie. Curso De Direito Processual Civil.Teoria da Prova, Direito Probatório, Decisão, Precedente, Coisa Julgada e Tutela Provisória $10^{\circ} \mathrm{Ed}$. Jusprovim. 2015. Salvador. Bahia. p. 568

${ }^{9}$ DIDDIER JR, Fredie. Curso de Direito Processual Civil, Teoria e Processo de Conhecimento, Introdução ao Direito Processual Civil e Processo de Conhecimento. Vol 1.ED PODIVUM, $14^{\circ}$ ed., 2012, Salvador - Bahia, p. 319.
} 
Pela breve citação exposta acima, pelo nobre professor Freddie ressalvada pelas palavras do brilhante desembargador aposentado do Tribunal de Justiça do estado de São Paulo Dr. Kazuo, fica claro que a tutela provisória, após terem sido analisadas, e também pela valorização das alegações das partes respectivamente pela produção de provas produzidas pelas mesmas, torna-se de forma inviável e também inquestionável a coisa julgada pela qual ambas (partes) almejam.

\section{AS ESPÉCIES DE TUTELA PROVISÓRIA: ANTECIPADA E CAUTELAR.}

As espécies de tutela provisória pelo novo código de processo civil em vigor lei 13.105/2015 divide-se em duas: a primeira antecipada (satisfativa - houve mudança na redação do nome pelo Senado federal) e a segunda a cautelar. Abordarei brevemente neste tópico o conceito das duas. A tutela provisória, tem por uma de suas características a sua definitividade situada pela concessão provisória de sua tutela. A tutela satisfativa e a cautelar também exauridas nesse trabalho são espécies de tutela provisória podendo assim antecipar provisoriamente a tutela do direito afirmado.

A tutela satisfativa (antecipada) é a antecipação dos efeitos da tutela definitiva, confirma-se assim o direito afirmado na ação de antecipação de tutela, almejando assim o direito afirmado. Como característica principal, satisfaz no todo ou em parte, o pedido formulado do autor, recebendo os efeitos ou ainda as consequências jurídicas que ele mesmo pleiteia com o ajuizamento da ação. Por isso destacamos que se a tutela fosse total em caráter permanente e não fosse provisório, o autor ficaria contente com a decisão e satisfeito completamente, contudo isso não será concreto porque ela é provisória e precisa ser trocada por uma decisão definitiva.

Já a tutela cautelar antecipa os direitos da tutela contraditória ou não satisfativa, conferindo assim a eficácia do direito a tutela, antecipando desta forma a cautela de determinado direito em relevância se o seu estado é de extrema urgência. Desta forma a tutela provisória cautelar tem dupla função a provisória por dar antecipadamente de forma eficaz à tutela contraditória ou não satisfativa e a segunda, é a cautelar que assegura futuramente a eficácia da tutela definitiva satisfativa, na proporção de resguardar o direito pleiteado a ser satisfeito. 


\subsection{ESTABILIDADE DA TUTELA ANTECIPADA.}

Como já relatado no presente trabalho uma das mudanças de enorme importância no CPC/2015, na tutela provisória foi a economia processual em que se refere a exclusão do processo secundário da ação cautelar de antecipação da tutela, sendo unificado na ação principal. Caso o réu não venha a intervir juridicamente com recurso de agravo de instrumento, perante a tutela que está sendo pleiteada a mesma torna-se estável, como descreve o art. 304 caput; e $\S 1^{\circ}$ ao $\S 6^{\circ}$ do CPC/2015, Caso o recurso não seja impetrado o processo será extinto.

Qualquer uma das partes poderá demandar a outra com o intuito de revisar, reformar, rever ou até a possibilidade de invalidar a tutela antecipada estabilizada caso não seja interposto o respectivo agravo de instrumento, conservando assim seus efeitos enquanto não revista.

Outro fator que proporciona a estabilidade da tutela antecipada, é o desarquivamento dos autos em que foi deferida a medida, para que seja feita a instrução da petição inicial a que se refere a sua modificação ou reforma, afirmando o juízo em que a tutela antecipada foi concedida. $\mathrm{O}$ direito que a parte tem de rever cancelar, modificar ou até invalidar a tutela antecipada extingue-se após dois anos, contados a partir da decisão que extinguiu o processo sem a impetração do recurso de agravo de instrumento.

Deferida a decisão, a tutela antecipada não fará coisa julgada, contudo a estabilidade dos respectivos efeitos só poderão ser anuladas por decisão que novamente proporcionar a reforma, modificação ou ainda a invalidação, contudo a ação deverá ser proferida e ajuizada por uma das partes, relatando o indeferimento do recurso.

Do mesmo modo a tutela não se estabilizará, se for interposto o recurso de agravo de instrumento, ocorrendo a extinção do processo, surge então estabilização reversível que será pleiteada na decisão que expira no prazo de dois anos contados da ciência que extinguiu o processo. Já a estabilidade irreversível ocorrerá, se for ultrapassado o prazo decadencial de dois anos, não havendo pedido de revisão, reforma ou invalidação. Ainda em caráter recursal devemos explanar para complemento do presente trabalho o Art. 1009, CPC/2015, que transcreve mediante sua Lei o recurso de apelação, isso ocorre quando a tutela e for concedida na sentença. 


\subsection{FUNDAMENTOS JURÍDICOS DA TUTELA PROVISÓRIA: A TUTELA DE URGÊNCIA E A TUTELA DE EVIDÊNCIA}

\subsubsection{A tutela de urgência}

A tutela de urgência esta elencada no Art. 300 à 302 do CPC/2015 onde descreve que para caracterizar o termo urgência deverá preencher elementos que evidenciem a probabilidade de direito e o perigo de dano ou risco ao resultado útil do processo. Para ocorrer sua efetivação na tutela de urgência o magistrado pode conforme o caso a ser analisado, exigir caução ou fidejussória de forma idônea para ressarcir os danos que a outra parte poderá sofrer. Art. $300 \S 1^{\circ} \mathrm{CPC}, 2015$. Onde a mesma poderá ser concedida liminarmente ou após as justificativas prévias que preencham os requisitos expostos no $\mathrm{CPC} / 2015$, Art. $300 \S 2^{\circ}$. Poderá haver a não concessão da tutela de urgência de natureza antecipada, quando ocasionar perigo ou ameaça de irreversibilidade referente aos efeitos da decisão. Art. $300 \S 3^{\circ} \mathrm{CPC} / 2015$. O arresto, sequestro, arrolamento de bens, registro de protesto contra alienação de bem são formas de efetivar a tutela de urgência, sendo de qualquer outra forma ou medida idônea para asseguração do direito. Art. 301 caput CPC/2015.

Também se caracteriza na tutela de urgência a responsabilidade independentemente se houver reparação processual ou não da parte adversa se resultar em sentença desfavorável, caráter antecedente referente à não citação do requerido, a cessação da eficácia ou ainda o acolhimento da decadência ou prescrição do autor, pelo magistrado. Art. 302, I, II, III, IV CPC 2015.

Cabe registrar no presente trabalho o procedimento da tutela antecipada requerida em caráter antecedente, frisa a urgência no presente código em seus arts. $303 \S 1^{\circ} \mathrm{I}$, II, III, $\S 2^{\circ}$ ao $6^{\circ}$ e o art. $304 \S 1^{\circ}$ ao $6^{\circ}$. Nos casos do art. 303 parágrafos, seguintes e seus respectivos incisos, em que a urgência for recente à propositura da ação, podendo a petição limitar-se ao requerimento da tutela antecipada e ao apontamento ou indicação da tutela final, expondo a lide ao direito que se deve buscar realizar, havendo ameaça ou perigo no resultado final útil do processo. Sendo concedida a tutela antecipada deverá ser feito por parte do autor o aditamento da inicial, com alterações (complementação), juntada de novos documentos e o mais 
impostante o pedido da tutela final em 15 (quinze) dias ou quando o magistrado fixar.

Ainda a parte ré será citada e intimada para audiência de conciliação ou de mediação na forma do art. 334 CPC/2015, caso não haja conciliação ou mediação segue-se os trâmites para a parte contestar, cujo o prazo será contato na forma do art. $335 \mathrm{CPC} / 2015$. Prosseguindo a fase processual não havendo a realização do aditamento da inicial será julgado extinto o processo sem a decisão de mérito, sem o surgimento de novas custas processuais. A parte autora ainda não deverá esquecer em hipótese alguma de na petição inicial o valor da causa levando em consideração junto ao pedido da tutela final, além se requer benefícios para si. Contudo não havendo elementos para que haja a concessão da tutela antecipada, o órgão jurisdicional determinará uma redução do prazo para a ementa de 15(quinze) para 5 (cinco) dias, sob punição de ser indeferido e sem resolução de mérito.

$\mathrm{Na}$ outra espécie de tutela a cautelar especificamente será requerida em caráter antecedente quando indicar na lide o seu fundamento, expondo sumariamente o direito objetivo, pelo fato de comprovar algum risco, dano no resultado útil do processo. Neste caso o réu será chamado ao processo e será citado no prazo de 5 (cinco) dias, para a contestação e informar as provas que queira produzir naquele momento, sendo o mesmo feito observar-se-á o procedimento comum. Não havendo contestação da parte ré presumir-se-ão verdadeiros os fatos dando o magistrado o mesmo prazo de 5(cinco) dias para a decisão.

Efetivada a devida tutela cautelar, será aberto o prazo de 30 (trinta) dias para a formulação do pedido principal pelo autor, apresentando nos mesmos autos a dedução do pedido da tutela cautelar, não criando novas custas processuais. Esse pedido poderá ser feito junto com a tutela cautelar, e ainda a causa de pedir poderá ser aditada com a formulação do pedido principal. No que concerne a apresentação do pedido principal feito pelo autor, as partes serão intimadas para que seja seguido o rito do art. 334 CPC/2015, por seus advogados sem necessidade de nova citação a parte ré. Não havendo autocomposição exerce-se o rito do 335 CPC/2015 para a contestação.

Contudo cessa-se sua eficácia quando o autor não deduzir o pedido principal no prazo concedido, o magistrado julgar improcedente o pedido formulado pelo autor, extinguindo o processo sem resolução de mérito, sendo vedado(proibido) a parte renovar o mesmo pedido salvo sob um novo fundamento. A diretiva negativa dada pelo magistrado, referente a 
concessão da tutela cautelar, não impede que a parte elabore o pedido principal, nem obsta qualquer influência no julgamento em andamento, salvo se o motivo da negação da tutela cautelar, basear-se na prescrição e decadência.

\subsubsection{Tutela de evidência}

Em seu art. $311 \mathrm{CPC} / 2015$, destaca a tutela de evidência que será concedida independentemente da demonstração de perigo ou dano de risco ao resultado útil do processo, isso ocorre quando caracterizado abuso do direito de defesa ou a manifestação protelatória da parte ou ainda quando forem feitas provas apenas na forma documental, e ainda a confirmação de teses relacionadas a julgamentos passados, ou em súmula vinculante. Ainda a evidência caracterizada por esse tipo de tutela faz-se em prova documental adequada em seu inciso III do Art. 311 do novo CPC, fala-se em contrato de depósito, onde pelo magistrado é decretada a ordem de entrega do objeto em questão, com pena de multa caso não seja exercida a função de entregar a mesma.

E por fim a maior das praticidades elencadas no trâmite processual, a tutela de evidência será caracterizada pela peça inicial do processo a petição quando a mesma estiver sobrecarregada suficientemente com provas documentais pelos fatos de direito arguidos pelo autor, em que o réu não tenha chance em hipótese alguma de gerar ou produzir prova em caráter de dúvida para o andamento da ação. O mais importante tanto para a afirmação dos fatos que só poderão ser comprovados por prova de espécie documental Art. 311, II, CPC/2015, quanto para pedido reipersecutório também sendo fundamentado em prova documental pela não entrega do objeto em questão será decido liminarmente pelo juiz em seu devido processo legal, sendo assim abreviando tempo e exercendo a economia processual entre as duas partes.

\section{CONSIDERAÇÕES FINAIS}

Em suma o novo CPC, veio simplificar um dos direitos mais pleiteados em nossos fóruns e tribunais, a tutela antecipada ganhou muito com a extinção do processo secundário ao qual era elaborado para a discussão 
de um segmento em particular dentre as partes dentro do processo, prejudicando assim, o andamento da ação principal. Com as inovações do CPC/2015, unificou-se na ação principal tudo o que deverá ser discutido, satisfazendo ambas as partes e facilitando tanto o julgamento para o magistrado, e procuradores no quesito do trâmite recursal, caracterizando assim a economia e a celeridade processual tornando o mais sucinto.

\section{BIBLIOGRAFIA.}

DIDDIER JR. Freddie. Curso De Direito Processual Civil. Teoria da Prova, Direito Probatório, Decisão, Precedente, Coisa Julgada e Tutela Provisória $10^{\circ}$ Ed. 2015. Jusprovim. Salvador. Bahia.

DIDIER JR. Freddie, Curso de Direito Processual Civil, Teoria e Processo de Conhecimento, Introdução ao Direito Processual Civil e Processo de Conhecimento. Salvador: JusPODIVM, 2012. Vol 1. DONIZETTI. Elpídio. Curso Didático de Direito Processual Civil. $19^{\circ}$ São Paulo: Ed. Atlas, 2016.

FUX, Luiz; NEVES, ASSUMPÇÃO, Daniel Amorim; Novo CPC Comparado. Código de Processo Civil Lei. 13.105/2015. $2^{\circ}$ Edição. Editora Metodo.

RIOS, GONÇALVES; Marcus Vinícius; Direito Processual Civil Brasileiro. Ed. Saraiva. São Paulo. $6^{\circ}$ Edição, 2016. 